\title{
Micrometric And Microanatomical Study of Papillary Muscles In Adult Human Hearts
}

\author{
*Dr. S.Kavitha, ${ }^{1}$ Dr.K.Y.Manjunath ${ }^{2}$, \\ ${ }^{1}$ Assistant Professor, Vinayaka Missions Kirupananda Variyar Medical College, Salem. \\ ${ }^{2}$ Professor, Annapoorna College Of Medical Sciences, Salem. \\ *Corresponding author: Dr. S.Kavitha
}

\begin{abstract}
:
Aim: To analyze histomorphometric features of papillary muscles in both ventricles of human heart.

Materials \& Methods: 50 human hearts specimens were used. $H$ \&E Stain and some special staining (trichrome) were made. Histotechnique procedure and Magnus pro histo analytic software was used to study morphometry.

Results: The length of right anterior papillary myocyte mean of $39.25 \mu \mathrm{m} \pm 11.95$ and right posterior papillary myocyte length mean of $27.66 \mu \mathrm{m} \pm 5.09$ and the length of septal myocyte mean of $34.15 \mu \mathrm{m} \pm 7.13$.The length of left anterolateral papillary myocyte mean of $42.54 \pm 6.45 \mu \mathrm{m}$ and length of left posteromedial papillary myocyte mean of $47.74 \mu \mathrm{m} \pm 9.99$.

In the present study width of right anterolateral papillary myocyte mean of $11.82 \mu \mathrm{m} \pm 3.62$. Right posteromadial papillary myocyte width mean of $7.14 \mu \mathrm{m} \pm 2.09$. The septal myocyte width mean of $9.72 \mu \mathrm{m} \pm$ 2.54. The width of left anterolateral papillary muscle fibre mean of $9.76 \mu \mathrm{m} \pm 2.61$. In the present study perimeter of papillary muscle cell nucleus mean was $68.76 \mu \mathrm{m}$.

Conclusion: The papillary myocyte size was smaller than the cardiac musclefibre including the nuclear size in majority of the cases the myocytes were binucleated and the nucleus was elongated.
\end{abstract}

Keywords: Histology, myocyte, nucleus.

Running Title: Microanatomy of papillary myocyte.

\section{Introduction}

Cardiac muscle fibres are both transversely and longitudinally striated. They can be conveniently divided into a) fibres of atria b) fibres of ventricles and c) fibres of conducting system of the heart. The ventricular fibres consist of superficial and deep ventricular layers. The superficial ventricular layers include:

1) Fibres which start from the infundibular tendon and curve across the diaphragmatic surface and sweep to the left, across the anterior interventricular groove to form a vortex round the cardiac apex, finally from the anterior half of the tendon it pass to the anterior and posterior papillary muscles from its posterior half to the anterior half.

2) Fibres from the right atrioventricular annulus which cross the diaphragmatic surface of the right ventricle reach its sternocostal surface. There they pass beneath the fibres just as described previously and cross the anterior interventricular groove to wind round the apex ending in the posterior papillary muscle of the left ventricle.

3) Fibres from the left atrioventricular annulus which cross the posterior interventricular groove pass into the right ventricle to end in its papillary muscles.

There are three deep ventricular layers, starting in the papillary muscles of one ventricle and curves sinuously into the anterior interventricular groove to end in the papillary muscles of the other. The most superficial layer in the right ventricle is deepest in the left and vice versa.

The first layer almost encircles the right ventricle which crosses the septum to the left and unites with the superficial fibres from the right atrioventricular ring to form the posterior papillary muscle.

The second layer is less extensive in the right ventricular wall and correspondingly greater in the left where it joins with superficial fibres from the anterior half of the infundibular tendon to form the septal papillary muscle. The third layer almost encircles the left ventricle to unite with superficial fibres from the posterior half of the tendon to form the anterior papillary muscle. The arrangement of these three layers helps to fully synchronize ventricular systole with the atrioventricular valve closure [1]. Cardiac muscle is the muscle of the heart. It consists of short and cylindrical muscle fibres, which branch and anastomosis with each other. Each fibre contains a single oval centrally placed large nucleus (fig: 1). Cardiac myocyte is about $80 \mu \mathrm{m}$ long and about $15 \mu \mathrm{m}$ broad. The muscle fibres attach to each other by special junctional complexes known as intercalated discs. These intercalated discs or junctional complexes appear as zigzag lines between the cardiac myocytes (fig: 2) and are caused by the opposing plasma membranes of the two cardiac muscle cells [2]. 
The abnormal thickness of papillary muscles is called papillary muscle hypertrophy. The myocardium hypertrophies because of hypertension, aortic stenosis, hypertrophic cardiomyopathy and end-stage kidney disease. Narrowing of the left ventricle due to enlargement and cardio myopathy can result in obstruction of flow from ventricles. The papillary muscle area during systole fractional shortening occurs due to left ventricular hypertrophy $(\mathrm{LVH})$. In addition to that the papillary muscle length in the affected hearts remains unchanged. Only the shape often changes produces thickening of papillary muscle [3].

There are three main types of artificial heart valves: the mechanical, the biological, and the tissue engineered valves.Two major types of artificial prosthetic valves are now available. Many reputed concerns manufacture artificial tissue based bio valves using polymers [4]. Many cadaveric studies have documented these facts but no study has been conducted on the microanatomical changes in the papillary muscles of adult human heart and morphological studies have been conducted only on atrioventricular valve on left ventricle only. Papillary muscle involvement affect the heart in most benign, acquired as well as congenital diseases making it an important constituent of effective heart function. So the subvalvular apparatus plays an important role in heart valve replacement surgeries of the modern era. While fixing of valve during replacement even a minimal difference in the measurements will be crucial for effective postsurgical functioning of the valve. There is a marginal difference in the measurements between the attachments of the chordae from the papillary muscle to the valve and the measurements between the papillary muscles to the valve.

\section{Materials And Methods}

50 fresh adult human hearts specimens were obtained from through the department of Forensic Medicine Vinayaka Mission Medical College Salem. The collected hearts specimens were immersed in the preservative $10 \%$ formalin solution containing (10 liters of normal saline with 1 liter of formaldehyde and $50 \mathrm{ml}$ of glycerin and $5 \mathrm{Gms}$ of powdered thymol were added). Papillary muscles in both ventricles of heart, the tissue bits were collected from middle portion of the papillary muscle in heart specimens and were processed for histological study. The tissue bits were immersed in fixative solution i.e. $10 \%$ formalin for one week. After fixation was complete the tissue bit were processed for paraffin embedding.

\section{Tissue processing involved the following steps:}

1. Hydration $\rightarrow$ 2.Dehydration $\rightarrow$ 3.Clearing $\rightarrow$ 4. Impregnation $\rightarrow$ 5.Casting $\rightarrow 6$. Staining $\rightarrow$ 7.Mounting

The sections were stained with Haematoxylin \& Eosin stains. Special stains like Masson trichrome and a PAS stain were used. Standard histopathological techniques were employed for the staining procedure [5]. The stained slides were photographed using a camera affixed to the Microscope. The Magnus Pro histo analytic software was used to study the histo morphometry.

\section{Papillary Myocyte Length \& Width Measurements}

In longitudinal sections, length and width of individual myocyte were measured using Magnus pro software (fig: 3 ). this measurement was done under $10 \mathrm{x}$ magnifications.

\section{Papillary Muscle Cell Nucleus Perimeter Measurement} (fig: 4).

In longitudinal sections, perimeter of the nuclei was measured using oil immersion objective (100X)

Using the formula given below the circumference of the nucleus was calculated

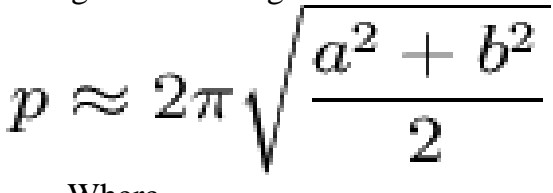

Where

$$
\begin{aligned}
& \mathrm{P}=2 *(3.14) \\
& \mathrm{a}=\text { maximum length of nucleus (major axis) } \\
& \mathrm{b}=\text { maximum width of nucleus (minor axis) }
\end{aligned}
$$

\section{Statistical Analysis}

The measurements were subjected to statistical analysis using SPSS (Statistical Package Social Service) software version 16. The range, standard deviation and mean were calculated. Chi square test was done to compare the variables. 


\section{Length of Papillary Myocyte}

\section{Results:}

In the present study the length of right anterior papillary myocyte ranged from 15.69 to $61.53 \mu \mathrm{m}$ with a mean of $39.25 \mu \mathrm{m} \pm 11.95$ and right posterior papillary myocyte length ranged from 19.56 to $41.14 \mu \mathrm{m}$ with a mean of $27.66 \mu \mathrm{m} \pm 5.09$ and the length of septal myocyte mean ranged from 18.88 to $54.38 \mu \mathrm{m}$ with a mean of $34.15 \mu \mathrm{m} \pm 7.13$ (table: 1 ). The length of left anterolateral papillary myocyte ranged from 29.01 to $55.94 \mu \mathrm{m}$ with a mean of $42.54 \pm 6.45 \mu \mathrm{m}$ and length of left posteromedial papillary myocyte ranged from 21.27 to 71.75 $\mu \mathrm{m}$ with a mean of $47.74 \mu \mathrm{m} \pm 9.99$ (table: 1 ).

In the present study the mean length of left posterior papillary myocyte was higher than all the other papillary myocyte. (Fig: 5).

\section{Width of Papillary Myocyte}

In the present study width of right anterolateral papillary myocyte ranged from 5.59 to $27.49 \mu \mathrm{m}$ with a mean of $11.82 \mu \mathrm{m} \pm 3.62$. Right posteromadial papillary myocyte width ranged from 2.44 to $13.82 \mu \mathrm{m}$ with a mean of $7.14 \mu \mathrm{m} \pm 2.09$. The septal myocyte width ranged from 4.35 to $15.02 \mu \mathrm{m}$ with a mean of $9.72 \mu \mathrm{m} \pm 2.54$ ( table:2)

The width of left anterolateral papillary muscle fibre ranged from 4.06 to $15.09 \mu \mathrm{m}$ with a mean of $9.76 \mu \mathrm{m} \pm 2.61$. The left posteromedial papillary muscle fibre width ranged from 4.38 to 16 . $49 \mu \mathrm{m}$ with a mean of $9.66 \mu \mathrm{m} \pm 2.52$ ( table:2).

In the present study the width of right anterior papillary myocyte was comparatively larger than that of all the other papillary myocyte (fig:6).

\section{Nucleus Length and Width of Papillary Muscle Cell}

In the present study the length of papillary muscle cell nucleus ranged from 68.88 to $113.37 \mu \mathrm{m}$ with a mean of $86.65 \mu \mathrm{m} \pm 23.55$. The width of papillary muscle cell nucleus ranged from 53.67 to $77.75 \mu \mathrm{m}$ with a mean of $68.19 \mu \mathrm{m} \pm 12.78$ (fig: 7 ).

\section{Perimeter of Papillary Muscle Cell Nucleus}

In the present study perimeter of papillary muscle cell nucleus mean was $68.76 \mu \mathrm{m}$. (table: 4 ).

\section{Discussion}

In cases of cardiomyopathy, the myocyte appears bulged with perinuclear clearing and replacement of transverse striations by eosinophilic granules indicating the increased numbers of mitochondria. The frozen sections of muscle fibre stained showed reduction in oxidative enzymes and electron microscopy showed abnormal mitochondria [6]. The normal human heart papillary myocyte size measured histologically is clinically very important, because the myocyte structures differs in many disease conditions particularly hypertrophic cardiomyopathy $[7,8]$.

In the present study the mean length of left posterior papillary myocyte was significantly higher when compared to the right posterior papillary myocyte (p>0.05) (table: 4).

In cases of dilated cardiomyopathy, the affected endocardium is opaque and white and may be up to several millimeters thick. The thickening affects the papillary muscles and extends into the trabecular ridges. The histological evidence of myocardial hypertrophy and fibrosis can visualize. Microscopically there is myocyte nucleus enlargement and hyperchromasia and the myofibrils are stretched and wavy [9]. In the present study histological findings of papillary muscle fibre was similar to other cardiac muscle fibres ; but some features differ from the general cardiac musculature; the papillary muscle fibre size was smaller including the nuclear size in majority of the cases the myocytes were binucleated and the nucleus was elongated. In other cardiac muscle fibres characteristically the nucleus was single oval and centally placed. In other features like striations, branching and the features of intercalated disc were similar to those of the cardiac muscle in papillary muscle also (fig:2) Sections of papillary muscle were also stained with PAS and Masson trichrome stains to see arrangement of the muscle fibres, connective tissue and collagen fibres (fig: 8).

\section{Conclusion}

In the present study, histomorphometric findings of papillary myocyte some features were different from the general cardiac musculature; the papillary myocyte size was smaller than the cardiac musclefibre including the nuclear size in majority of the cases the myocytes were binucleated and the nucleus was elongated.

Very few studies for histomorphometric analysis of papillary muscle exist, hence this study is unique. So in the present study differs from the previous studies by presenting images of all types of papillary muscle 
patterns. This data will be helpful and relevant for cardiac surgeons performing mitral valve and tricuspid valve homograft implantation procedures.

\section{ACKNOWLEDGEMENTS}

The authors sincerely wish to thank the management, administrators and the Professor and Head of the department of Anatomy and Forensic Medicine of Vinayaka Missions Kirupananda Variyar Medical College, Salem for their whole hearted support and permissions to utilize their resources and conduct this study. The authors acknowledge the great help received from the scholars whose articles cited and included in references of this manuscript. The authors are also grateful to authors/editors/publishers of all those articles, journals and books from where the literature for this article has been reviewed and discussed. Authors are grateful to IOSR (JDMS) editorial board members and IOSR (JDMS) team of reviewers who have helped to bring quality to this manuscript.

\section{References}

[1]. Susan Standring. Gray's Anatomy, 39 ${ }^{\text {th }}$ Edition. Anatomical basis of clinical practice, Churchill Livingstone, London. 2005; 39:1008

[2]. Eroschenko VP. DiFiore's Atlas of Histology with Functional Correlations $11^{\text {th }}$ Edition. Andersons KE \& Michel Mc (Eds), Lippincott Williams \& Wilkins Philadelphia. 2008; Pp: 117- 128

[3]. Madu EC, Reddy RC, Cruz Ia. Tee Assessment of Papillary Muscle Anatomy and Contraction in Patients with and Without Left Ventricular Hypertrophy. Journal of American College Cardiology. 1996; 27, (2): 350- 352.

[4]. Braunwald Ns, Cooper Ts, Morrow Ag. Complete Replacement Of The Mitral Valve. Journal of Thoracic Cardiovascular Surgery. 1960; 40: 1-11.

[5]. Cullings CFA. Text book of Histopathological and Histochemical Techniques $3^{\text {rd }}$ edition. Butterworth, London.1974; pp: $151-187$.

[6]. Taylor GP. Neonatal Mitochondrial Cardiomyopathy. Pediatric Developmental Pathology. 2004; 7:620-624.

[7]. Kobashi A, Suwa M, Ito T, Otake Y, Kawamura YK. Solitary Papillary Muscle Hypertrophy as a Possible Form of Hypertrophic Cardiomyopathy. Japanese Circulation Journal. 1998; 62:811-816.

[8]. Ashworth M. Cardiomyopathy in Childhood: Histopathological and Genetic Features. The Open Pathology Journal. 2010; 4:80-93.

[9]. Gilbert - Barness G, Barness La. Nonmalformative Cardiovascular Pathology in Infants and Children. Journal of Pediatric Development Pathology.1999; 2: 499- 530.

Tables and figures:

\begin{tabular}{|c|c|c|c|c|c|}
\hline \multicolumn{6}{|c|}{ TABLE:1 LENGTH OF PAPILLARY MYOCYTE IN BOTH VENTRICLES } \\
\hline \multirow{2}{*}{ N-50 } & Right Ventricle Papillary Myocyte $(\mu \mathrm{m})$ & Left Ventricle Papillary Myocyte $(\mu \mathrm{m})$ \\
\cline { 2 - 6 } & Anterior & Posterior & Septal & Anterior & Posterior \\
\hline \multirow{2}{*}{ Mean \pm SD } & $39.25 \pm 11.95$ & $27.66 \pm 5.09$ & $34.15 \pm 7.13$ & $42.54 \pm 6.45$ & $\mathbf{4 7 . 7 4 \pm 9 . 9 9}$ \\
\hline \multirow{2}{*}{ Range } & $15.69-61.53$ & $19.56-41.14$ & $18.88-54.38$ & $29.01-55.94$ & $21.27-71.75$ \\
& & & & & \\
\hline
\end{tabular}

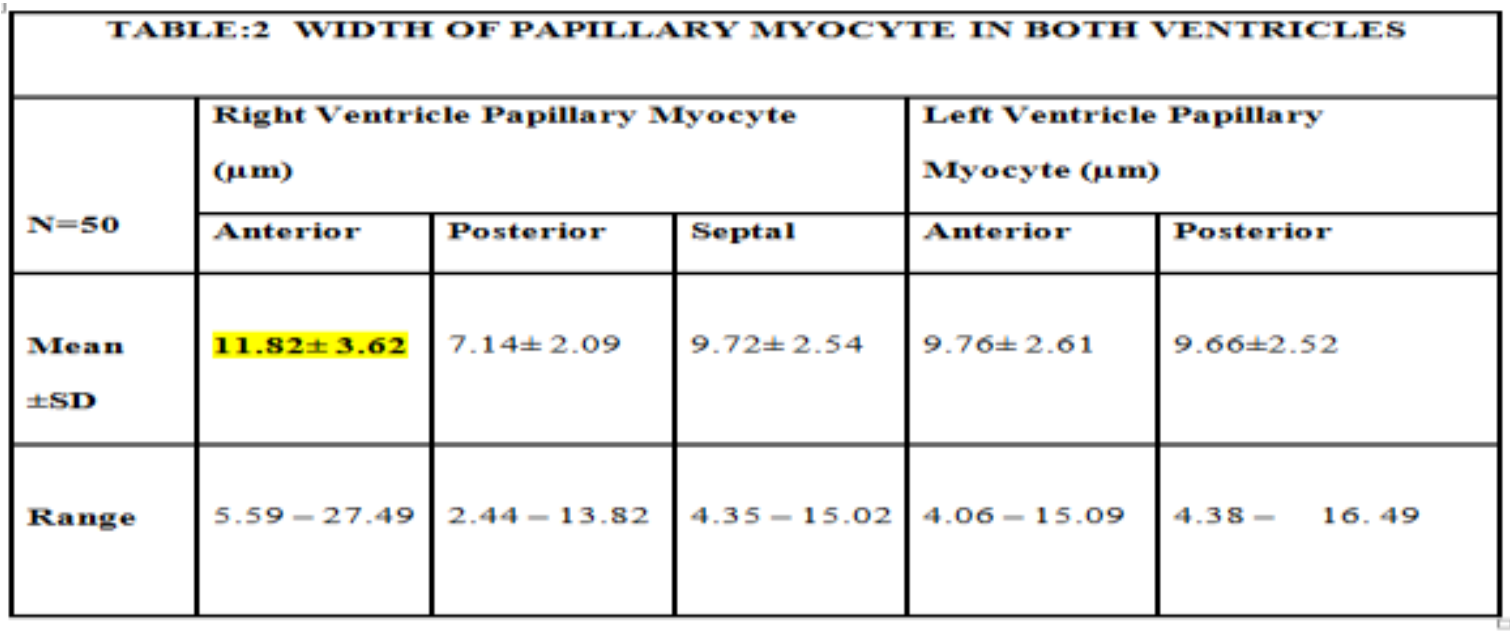


Micrometric and Microanatomical Study of Papillary Muscles in Adult Human Hearts

\begin{tabular}{|l|l|l|}
\hline \multicolumn{2}{|l|}{ TABLE: 3 Perimeter of Papil lary myocyte cell nu cleus } \\
\hline \multirow{3}{*}{$N=50$} & Mean ( $\mathrm{\mu m})$ & SD \\
\cline { 2 - 3 } & 68.76 & 15.21 \\
\hline
\end{tabular}

\begin{tabular}{|c|c|c|c|c|c|c|c|c|}
\hline \multirow[t]{2}{*}{ Pair } & \multirow[b]{2}{*}{ Mean } & \multirow{2}{*}{$\begin{array}{l}\text { Std. } \\
\text { Deviation }\end{array}$} & \multirow{2}{*}{$\begin{array}{l}\text { Std. } \\
\text { Error } \\
\text { Mean } \\
\end{array}$} & \multicolumn{2}{|c|}{$\begin{array}{l}95 \% \text { Confidence } \\
\text { Interval of the } \\
\text { Difference }\end{array}$} & \multirow[b]{2}{*}{$\mathbf{T}$} & \multirow[b]{2}{*}{ Df } & \multirow[t]{2}{*}{$\begin{array}{l}\text { sig. } \\
2 \text { taile } \\
\text { d }\end{array}$} \\
\hline & & & & Lower & Upper & & & \\
\hline $\begin{array}{l}\text { Myocyte length of } \\
\text { Right APM- Left } \\
\text { APM. }\end{array}$ & -3.292 & 11.389 & 1.610 & -6.529 & -.055 & -2.044 & 49 & .000 \\
\hline $\begin{array}{l}\text { Myocyte length of } \\
\text { Right PPM- Left } \\
\text { PPM }\end{array}$ & -2.008 & 10.583 & 1.496 & -23.089 & -17.073 & -13.416 & 49 & .046 \\
\hline
\end{tabular}

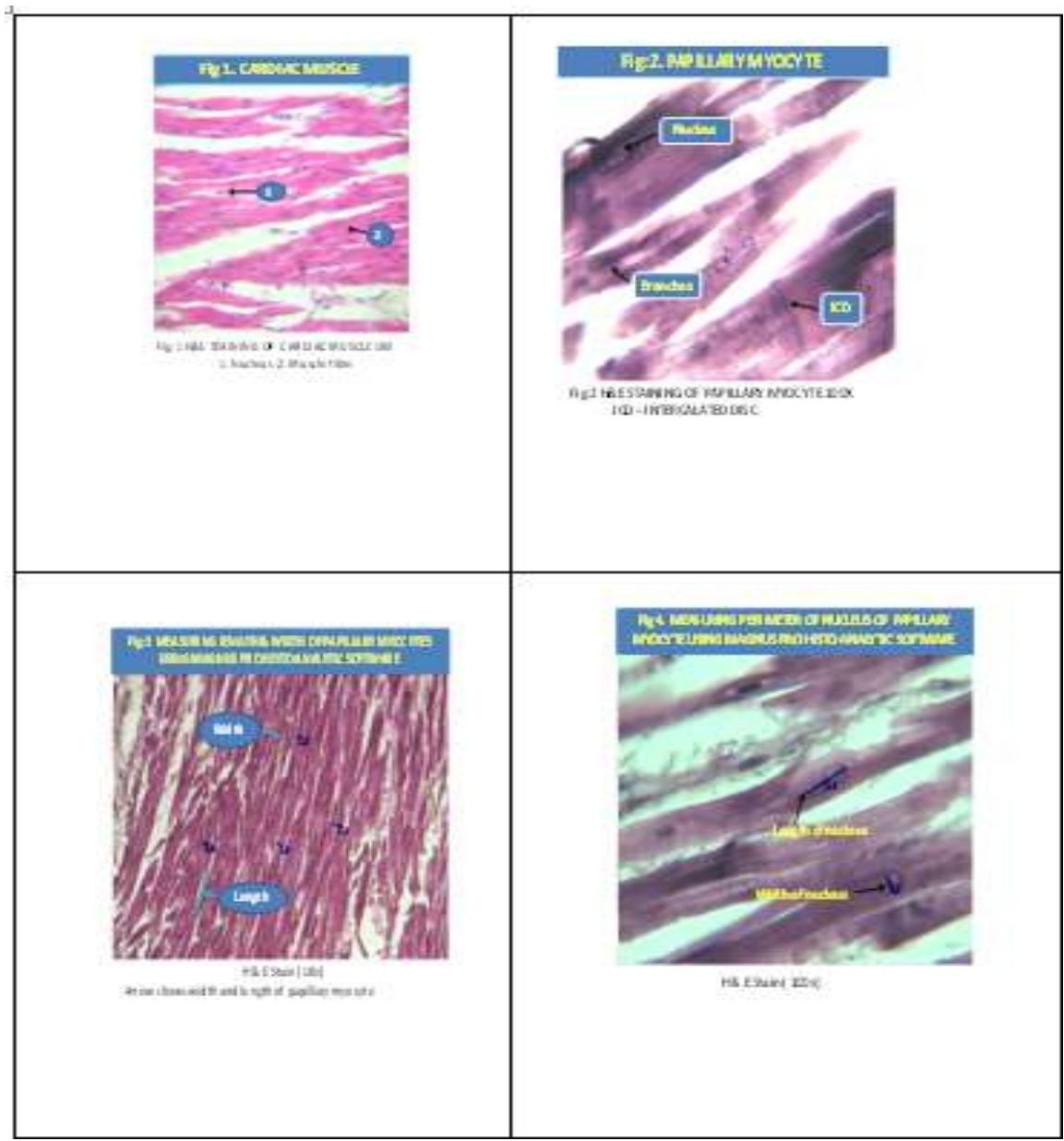



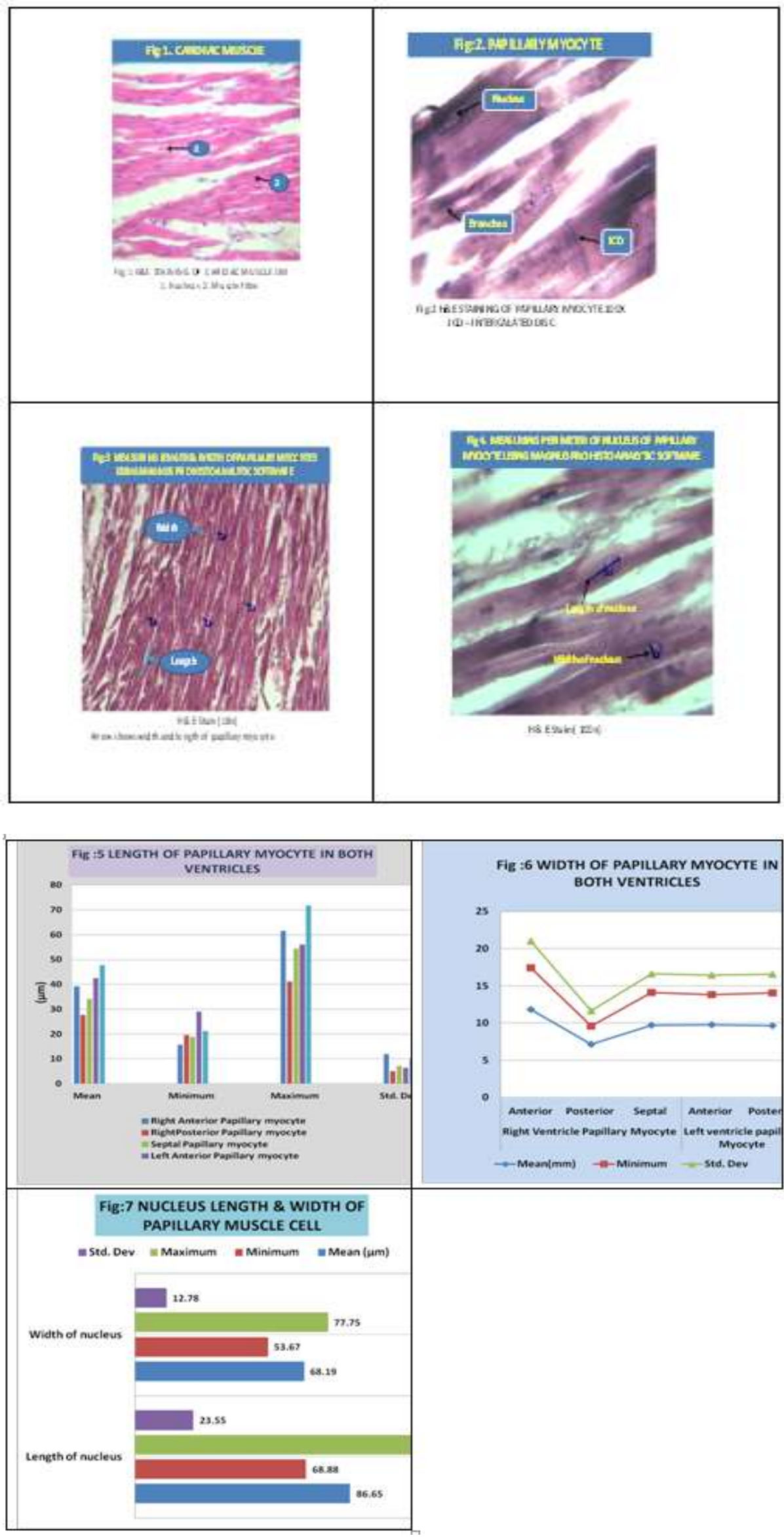


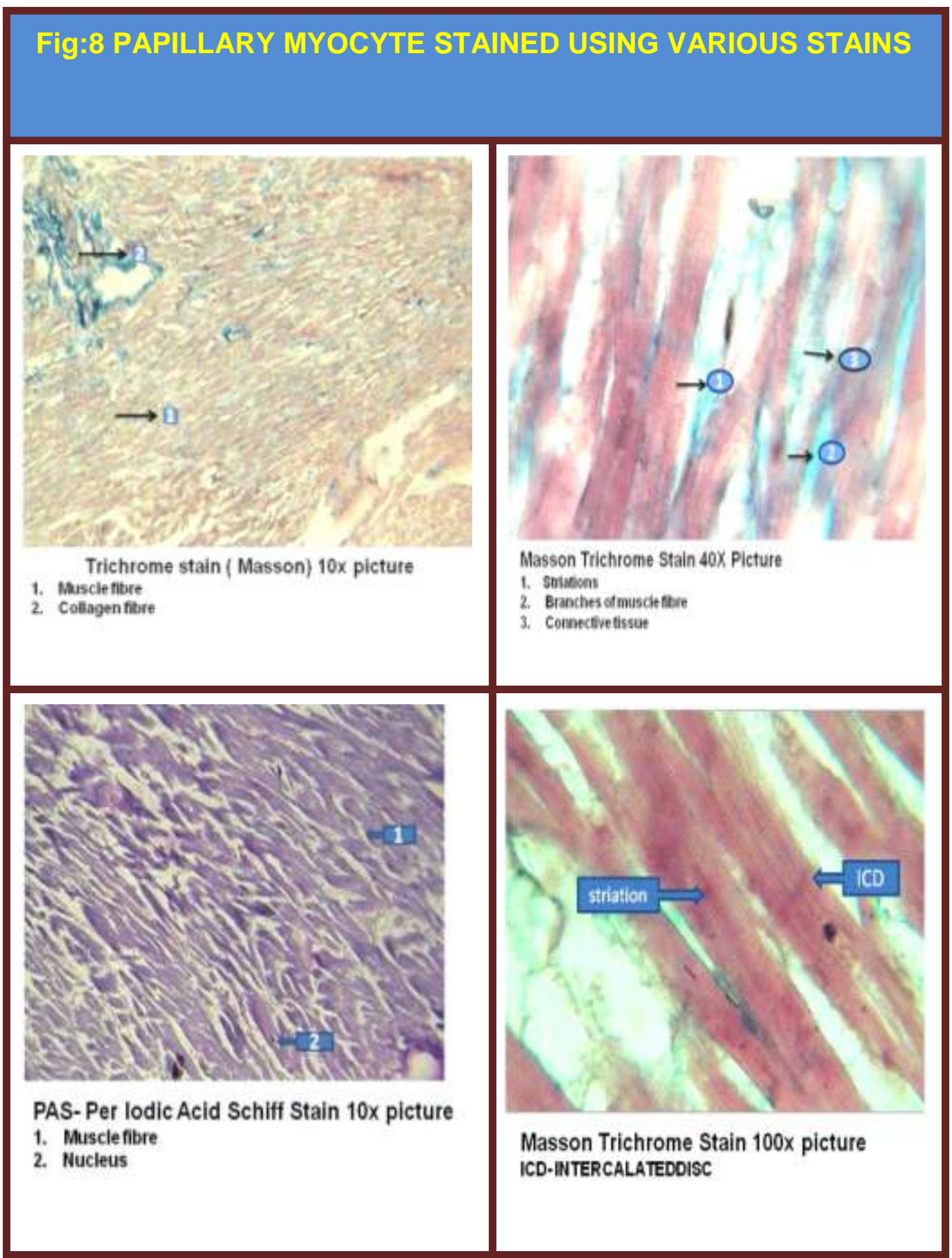

